\title{
Prevalence and factors associated with obesity in the patient followed in psychiatry
}

\author{
1,2Ghanmi L, 1,2Abbes W, ${ }^{1}$ Abbes M, ${ }^{1}$ Farhat D, ${ }^{1} \mathrm{~B}$ Chayeb, ${ }^{1}$ Elbehi M, ${ }^{1}$ Hamrouni S, \\ 'Salem O, ${ }^{1}$ Zitoun $\mathrm{K},{ }^{2,3}$ Denguir $\mathrm{H}$ \\ ${ }^{1}$ Psychiatry Department, Regional Hospital of Gabes. Tunisia \\ ${ }^{2}$ Faculty of Medicine of Sfax. Tunisia \\ ${ }^{3}$ Cardiology Department, Regional Hospital of Gabes. Tunisia.
}

\section{Introduction:}

Obesity is a common problem in psychiatric patients. It is associated with significant physical morbidity and a decrease in the quality of life of these patients.

\section{Aims:}

* To measure the prevalence of obesity in a population of patients followed in psychiatry in Gabes (southern Tunisia)

* To determine the factors associated with it.

\section{Methods:}

- A cross-sectional, descriptive and analytical study.

- We included all patients who consulted during the study period (regardless of diagnosis and who gave their consent).

- A semi-directive interview with the patient and a member of his family.

- The diagnosis of mental disorders: Diagnostic and Statistical Manual of Mental Disorders (DSM-5)

- Estimating obesity: body mass index (BMI)

$$
\begin{aligned}
& \text { Overweight }=\text { BMI between } 25 \text { and } 29.9 \mathrm{~kg} / \mathrm{m} 2 \\
& \text { Obesity = BMI } \geq 30 \mathrm{~kg} / \mathrm{m}^{2}
\end{aligned}
$$

Results:

$>115$ patients (TABLE 1: characteristics of our sample)

$>$ The mean $\mathrm{BMI}=25 \mathrm{~kg} / \mathrm{m} 2$

$$
\left\{\begin{array}{l}
\text { Overweight: } 40.9 \% . \\
\text { Obesity: } 49 \% .
\end{array}\right.
$$

> Obesity was significantly more common among women, living in couples (FIGURE 1, 2).

$>$ There were no differences between obese and non-obese patients in socioeconomic status, educational level, occupation and diagnosis.

\section{DISCUSSION:}

- Rates of obesity are higher than normal across a range of psychiatric disorders, including major depressive disorder, bipolar disorder, schizophrenia and anxiety disorders [11].

\begin{tabular}{|c|c|c|}
\hline \multicolumn{2}{|c|}{ Variable } & Percentage \\
\hline & Male & $59.1 \%$ \\
\hline Civil status & Female & $40.9 \%$ \\
& Living in couples & $40 \%$ \\
& Living alone & $60 \%$ \\
\hline Professional & Working & $29.6 \%$ \\
\hline activity & D'ont working & $70.4 \%$ \\
\hline Socio-economic & Low & $20 \%$ \\
\hline level & Medium & $76.5 \%$ \\
\hline Sports activity & High & $3.5 \%$ \\
& Yes & $9.6 \%$ \\
\hline & No & $90.4 \%$ \\
\hline
\end{tabular}

TABLE 1: Characteristics of our sample 